\title{
Paul Claudel, Marcel Proust y Paul Valéry
}

(Conferencia pronunciada en la Universidad de Chile, el 17 de Junio de 1924).

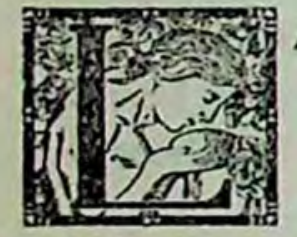

A conferencia que tengo el honor de pronunciar esta tarde ante vosotros surgió de una conversación cordialísima que, hace algunas semanas, luve con el muy distinguido rector de esta Universidad, don Gregorio Amunátegui. Hablamos del extenso público que. en general. hallan en Chile los autores franceses. y. como le expresara yo mi pesar porque una gran parte de nuestros escritores de hoy fuesen, a pesar de todo. casi ignorados aqui y. particularmente, porque los maestros de nuestras nuevas escuelas no han alcanzado sino hasta un grupo privilegiado. infinitamente reducido si se lo compara con el número de lectores con que cuentan ya en Francia. en Inglaterra y en los paises de la Europa central, don Gregorio Amunátegui me insinuó: ¿¿Por qué no les consagra usted una conferencia para nuestros estudiantes?. Mi amable interlocutor no comprendió. sin duda. el peligro de esta pregunta. sino cuando inmediatamente me oyó responderle por una aceptación de principio. Si esta tarde tengo el placer de ocupar vuestra atención en tres de los más grandes o. más exactamente. en los tres más grandes escritores franceses contemporáneos. y si sufris vosotros la indulgente molestia de escucharme. la culpa es. pues, de aquella pregunta comprometedora de vuestro rector $y$. en segundo lugar, de la apresurada indiscreción con que yo mismo respondí a ella.

Desde luego. os rogaria yo con encarecimiento que olvidarais. como yo mismo lo hago. las funciones oficiales que tengo el honor de desempeñar aqui y de no ver en mi sino a un joven escritor francés que os expone con toda sinceridad y con toda libertad sus ideas y las de su generación, y que se esfuerza en haceros conocer, y sobre todo en sugeriros el deseo de conocer, a los Maestros que más estimamos. Las perifrasis de la diplomacia son una cosa: la libertad de la crítica es algo diverso, y si en mi camino maltrato algunos ídolos de 
cartón, con esta advertencia busco limitar hasta su mínimum el escándalo que esto pudiera producir.

Algunos minutos de explicaciones preliminares parécenme necesarios antes de tratar el objeto mismo de esta conferencia: los consagraré a exponeros brevemente una de las condiciones más particulares de la vida literaria francesa desde hace tres cuartos de siglo: es su división en dos grandes corrientes distintas. divergentes aún, de las cuales una corre como un Pactolo. entre plantios rozagantes, bajo la enternecida mirada de los editores, para ir finalmente a sepultarse en la noche infinita de las bóvedas académicas, y la otra es el débil hilillo de agua que brota de la roca sagrada, parece perderse en los desiertos. pero un dia surge como una oleada en el corazón de los oasis eternos.

para ser claro, os haré un cuadro, por fuerza demasiado esquemático. y por lo mismo algo inexacto. de estos hechos. Pero. en la multitud de detalles contradictorios que se podrian acumular hasta lo infinito, se conservan las líneas generales, y son éstas lo único que importa observar.

Asi es como. si lo queréis arbitrariamente. fijaré en el año 1857 el punto de partida de estas dos corrientes divergentes, el comienzo de este divorcio en la literalura francesa, que. casi imperceptible en sus principios, ha ido acrecentándose hasta los primeros años del siglo XX. y cuya existencia nos explica cómo un número relativamente considerable de grandes escritores franceses ha quedado durante todo este periodo. ignorado o desconocido de la inmensa mayoria del público francés y extranjero.

En 1857, en efeclo, la gran lucha entre clásicos y románticos puede considerarse como terminada provisionalmente por la brillante victoria de estos últimos: victoria fácil, pues los héroes del romanticismo no combatieron sino contra los viejos y los muertos. y todas las fuerzas revolucionarias. todas las aspiraciones democráticas de la época. habian conspirado a favor suyo. La misma Academia Francesa habia debido terminar por abrirles sus puertas. Ninguna consagración oficial faltaba a la escuela trunfante y esta unidad de la literatura francesa. este asentimiento casi unánime del público. tales como existian casi sin interrupción desde sus comienzos, parecian de nuevo definitivamente adquiridos.

Ahora bien. en 1857, aparecieron dos libros. de valor literario desigual. pero de la misma importancia histórica. Uno de ellos. ¿Les Fleurs du mals de Charles Baudelaire. la más grande recopilación de poemas del siglo XIX: el otro era .Madame Bovary,. de Gustave Flaubert. Del libro de Baudelaire ha nacido toda la poesía moderna posterior al romanticismo: es decir. todo lo que en el inmenso conjunto de la producción poética de los últimos setenta y cinco años. merece el nombre de poesia. Sin el libro de Flaubert. toda la novela realista y naturalista de la misma época no habria sido lo que fué: las novedades de estilo del autor debian ejercer pronto una influencia segura en el lenguaje y en el vocabulario de las escuelas parnasiana y simbolista. Ahora bien, sabéis que estos dos libros. denunciados por una torpe critica. lueron perseguidos ante los tribunales. Flaubert fué absuelto; pero Baudelaire. condenado.

Parece que el célebre juicio que pretendió aniquilar. Les Fleurs du mal. 
marcó en cierto sentido el punto de partida de ese divorcio ruidoso que echó fuera de la literatura oficial, consagrada, recompensada, a la literatura creadora. original, de la época. La Academia Francesa, cuya creación remonta, como lo sabéis, hasta el Cardenal Richelieu, no debía desempeñar sino a partir del siglo XIX ese papel soberano de juez o de árbitro de las letras francesas que ha asumido, no me atrevo a decir usurpado, en Francia al principio, y, sobre todo hoy, ante el juicio extranjero. Durante mucho tiempo toda una parte de la opinión pública, tanto entre nosotros como afuera, ha aceptado sus juicios sin apelación, y se ha remitido a ella para la selección de sus lecturas. Llegar a ser uno de los cuarenta inmortales equivalia a aparecer como uno de los cuarenta mejores escritores franceses; digamos uno de los treinta. para dejar aparte la decena de personalidades de la politica, del episcopado o del mundo de las ciencias, que la Academia a tenido siempre por costumbre llamar a su seno, por razones muy visiblemente extrañas a la literatura. Un escritor de esta época que aspirara a sllegar,. si no se sentía con fuerzas para derribar por si mismo las columnas del templo, debía, pues, buscar en primer término hacerse premiar por la Academia Francesa, ya que los premios literarios, que han llegado a ser hoy tan numerosos como los dias del año, sólo eran discernidos. en número escaso. por esta honorable institución; en segundo lugar, debía ver manera de eser uno. algún dia, es decir, doblegar su estilo y su cerviz, desde su juventud, a las exigencias de esta falsa Minerva, y si había manifestado en sus comienzos la sombra de un talento original. consagrar el resto de su vida a una honrosa enmienda.

Es que, en efecto. este papel de árbitro soberano que la Academia Francesa habría podido ejercer. como en varias ocasiones en lo pasado, para el más fecundo desarrollo de las letras francesas, lo ha puesto en la segunda mitad del siglo XIX. voluntariamente, deliberadamente, al servicio de la rutina y de la medianía. Antes de esta fecha de 1857, en que quiero señalar el comienzo de una era nueva; y hoy. en pleno florecimiento de nuestra literatura, vemos que la Academia Francesa, después de un periodo de resistencia, muy comprensible por lo demás, habia terminado por conceder al romanticismo la consagración que le era debida. Hugo. Lamartine. Vigny. Musset formaban parte de los famosos cuarenta. Puede decirse que en esa fecha la Academia Francesa había reconocido y honrado casi a todos los maestros de nuestra literatura que entonces vivian. Digo casi porque, en fin, ella no habia reparado en Nerval, habia igno. rado a Stendhal, abandonado a Michelet y concedido sólo dos volos a Balzac cuando, en 1849. le hizo el honor de solicitar su incorporación. Pero después de 1857. son incontables los grandes nombres de nuestra literatura que faltan a su gloria. sea que ella haya rehusado formalmente elegirlos, sea que estos escritores hayan comprendido por sí mismos la inutilidad y aun lo risible de una tentativa de su parte. Y enumerar los nombres de estos artistas. es. con algunas excepciones tal vez, enumerar justamente esta segunda corrienle de nuestra literatura de que os hablaba al comenzar. de la cual teníase al público cuidadosamente aparte, lista en que por la primera vez en nuestra historia, vemos figurar 
a los que se ha llamado los escritores malditos, a los autores considerados difíciles a quienes se reservaba el derecho de gritar en un desierto. donde las piedras no se cambiaban en pan.

Ciertamente, entre estos excluídos de hecho o de derecho, encontramos algunos que han sabido hacer su camino sin la Academia y que se han vengado de su desprecio desdeñando su consagración: asi Flaubert; así Alfonso Daudet: así Emilio Zola: asi los dos hermanos Goncourt, quienes debían lundar por testamento la Academia que lleva su nombre y que ha prestado a las letras francesas tantos servicios efectivos en veinte años de existencia, como su hermana mayor en poco menos de un siglo. Pero, al lado de esos grandes nombres de la novela francesa, a los cuales la Academia ha preferido obstinadamente los Cherbuliez, los Eduardo Rod, los Octavio Feuillet, los Jules Claretie, es decir. las aproximaciones más inmediatas de la nada, icuántos artistas hoy gloriosos. creadores de un arte nuevo. maestros de las escuelas vivientes, ha dejado en una obscuridad y un silencio que no permitía al gran público francés y extranjero ni aun la sospecha de su existencia!: Baudelaire, desde luego, cuya candidatura fué considerada cierta vez como una mistificación. y Villiers de I'Isle Adam. y Barbey d'Aurevilly, y Pablo Verlaine, y Mallarmé, y Jean Moréas, y Henri Becque. y Fustel de Coulanges. No cito sino algunos de los muertos, y podría prolongar extensamente la lista con nombres de vivos. Siempre se dirige su elección a los talentos más apagados, más artificiales. A Verlaine, prefiere Coppée; a Mallarmé, Jean Aicard; a Becque. Paulo Hervieu; a Courteline. Francois de Curel: cuando se trata de dar su lugar a una escuela tan importante como la simbolista. llama a su más mediano representante, Henri de Régnier. No premia sino el éxito, sin preocuparse por la calidad, sin darse el lujo de descubrir un talento ignorado. Y como, a pesar de todo. durante años. en Francia y en el extranjero, ella siguió siendo la inspiradora de la crítica y de los lectores, ha ocurrido que grandes escritores tan cercanos a nosotros, tan accesibles como un Barbey d'Aurevilly, un Charles-Louis Philippe, un Francis Jammes, quedan ignorados de una multitud de espiritus perfectamente capaces de apreciarlos. pero que, faltos de guía, creen firmemente, con la autoridad de la Academia Francesa y de las instituciones que la realzan, que Edmond Rostand es un poeta, Henri Bordeaux un novelista y $M$. René Doumic un crítico literario.

Después de la guerra. felizmente, las cosas han cambiado algo. y. bajo la influencia de factores que sería muy extenso enumerar. esta conspiración del silencio se ha roto por veinte partes a la vez; hombres de un genio tan eminente como los tres autores a quienes he querido consagrar esta conferencia. atraen de día en día un público cada vez más numeroso, y los criticos académicos o academizantes que aun pretenden ridiculizarlos, como ese pobre $M$. André Beaunier, no predican ya sino para el diezmado auditorio de algunos salones adormecidos. Todo lo que vale algo, todo lo que vive en el mundo de las letras. les ha prestado acogida, y los mismos que los discuten, reconocen de esta manera su importancia. Por otra parte, los jóvenes que verdaderamente tienen algo auténtico que decir, una sincera experiencia que revelar, no corren ahora el peligro 
de quedar, como sus antecesores, en la sombra y en la indigencia. Una magnifica floracion de talentos nuevos ha aparecido en Francia desde hace diez años, y si entre éstos han podido deslizarse algunas reputaciones ficticias, os aseguro que es cien veces preferible que un renombre usurpado, que por si mismo se destruirá. se beneficie con una publicidad que al mismo tiempo sirve a los escritores de valor, y no ver a éstos vegetar toda la vida a la espera de una gloria que no debe ser sólo el sol de los muertos.

Me han parecido necesarias estas pocas palabras de explicación al comienzo de una conferencia consagrada a tres autores incorporados a esa línea de escritores que vivieron durante tres cuartos de siglo alejados de la literatura académica y oficial. los únicos que hayan aportado a nuestra literatura elementos de renovación. Os extrañaréis menos de no haberlos oído nombrar jamás en Chile o sólo muy escasamente, al saber que en Francia misma, hace diez años, su nombre sólo era conocido en un grupo selecto.

\section{I.-PAUL CLAUDEL}

Paul Claudel nació en Villeneuve, en el Oise, el seis de Agosto de 1868. Desde joven. se preparó para la carrera diplomática y consular, a la cual ingresó muy temprano y en la que ocupó sucesivamente los cargos de Cónsul en Boston, en Han-Keou, Foutchou, Schanghay; su estada en la China duró más de diez años y ejerció marcada influencia en su arte. o más exactamente. dotó a su genio de rica materia original. Fué nombrado después Cónsul General en Praga. en Frankfort, en Hamburgo, donde le sorprendió la guerra; después. Agregado Comercial en Roma. Ministro de Francia en Río de Janeiro, donde tuve el honor de servir a sus órdenes. Ministro en Dinamarca y por fin. Embajador en Tokio. donde se halla actualmente. En suma, una carrera extremadamente brillante y enteramente justificada por cualidades profesionales de primer orden. Pues este gran dramaturgo y gran lírico es igualmente un gran hombre de negocios, cuya poderosa imaginación sabe animar las cifras y las estadísticas y moverse en medio de los problemas modernos más complejos sin perder jamás el contacto con la realidad.

Esta exactitud en todos los negocios de su oficio o de la vida profesional es una de las primeras características de este hombre extraordinario: su profunda fe religiosa. o. más exactamente, el carácter de su conversión y la psicologia de su Credo, constituyen otra. El mismo ha relatado su conversión en una página admirable que lamento no haber podido encontrar aqui. Dice alli, en substancia, que hasta la edad de dieciocho años habia vivido en la más completa incredulidad, en la ignorancia total del catolicismo y sin concebir que el universo pudiera ser ofra cosa que una mecánica bien montada, pero regida en todos sus grados por el determinismo más absoluto. En esta época Les Illuminations de Arthur Rimbaud. que una pequeña revista La Vogue, acababa de publicar, cayeron en sus manos. y la lectura de estos poemas casi sobrenaturales obró ya en él una profunda revolución: le reveló que había entre las cosas otras relaciones que las 
puramente matemáticas y que era posible la existencia de un doble espiritual de este universo. La influencia de Arthur Rimbaud, de la cual ninguno de entre nosotros se atrevería a hablar sino con un sagrado respeto, fué decisiva sobre Paul Claudel: .Otros escritores me han instruido, ha escrito él. pero Rimbaud es el único que me ha construído: ha sido para mi la revelación en un momento de profundas tinieblas, el iluminador de todos los caminos del Arte. de la Religión y de la Vida; de tal suerte. que me es imposible imaginar lo que yo hubiera sido sin mi encuentro con este espiritu angélico. ciertamente esclarecido por la luz de lo alto. Principios, pensamientos, la forma misma, todo se lo debo, y siento que me liggan a él los lazos que pueden unirnos a un ascendiente espiritual. .

Pero Rimbaud, que era un ser fundamentalmente arreligioso y ateo. se hallaba separado por abismos de un catolicismo que Claudel aun no sospechaba. Pasaron uno o dos años, y un día de Pascua, pasando frente a Notre Dame. entró allí por ocio y para buscar ese género de emoción estética, me ha dicho. que un joven poeta simbolista podia esperar. La misa desplegaba sus esplendores litúrgicos y, repentinamente, sumergido como en un torrente de luz. Claudel sintió que ahí estaba la verdad, que ahí estaba ese sentido y ese secreto del mundo de que Rimbaud le habia dejado la inquietud, y de golpe, totalmente, para siempre, se convirtió. Los creyentes verán en esto la irrupción irresistible de la Gracia, el llamamiento imperioso que, desde San Pablo hasta Lacordaire, parece dirigirse con una impetuosidad más poderosa a los grandes activos. Los incrédulos no pueden sino respetar toda la sinceridad y el valor moral de una adhesión tan apasionada. Y lo que hay de singular es que esta religión que acababa de conquistarle tan absolutamente, era casi totalmente ignorada de Claudel. No sabía de ella sino la antipatia que sintió siempre hacia sus ministros y sus prácticas, y que subsistia enteramente en él, y hay también de extraño que la protesta de su razón ante los dogmas seguía siendo igualmente fuerte. Fué preciso más de un año para que esta posesión de conjunto llegara a ser en cierta manera una posesión en detalles de su alma, y para que esta conquista fuera seguida de la sumisión. Desde entonces, en todas las latitudes y en todos los paises. Cónsul. Ministro, Embajador, poeta, dramaturgo. Paul Claudel ha sido siempre el hombre que lleva siempre un rosario en su bolsillo y que todas las mañanas sale tranquilamente de su casa para oir la misa del alba.

He insistido acerca de estos detalles porque precisan todo un aspecto de la fisonomía del hombre y por la parte esencial que sus creencias han tenido en su obra. Está ésta impregnada de catolicismo. o más precisamente. de espiritu católico: es decir. ella crece y se desarrolla en un universo en que las jerarquías son jerarquias católicas. Es por esto. desde luego, por lo que es comparable a la obra del Dante; asi mismo porque estas jerarquias se conservan como jerarquias humanas. El creyente se arrodilla; pero se arrodilla sobre la tierra; en una iglesia humilde, arraigada al suelo y a los siglos. En el pórtico de esta iglesia. un artista francés ha esculpido las escenas de la vida cotidiana y los trabajos de las estaciones y los días. El gran peligro para un artista católico está en remontarse a las cimas inaccesibles de la mística, o bien, en caer en el tedio de las 
obras edificantes. El genio de Claudel ha evitado constantemente este doble escollo. En sus dramas, no hace selección entre lo real; no poda la vida; aun establece jerarquías, pero no suprime nada. En sus poemas ora a menudo y con acentos magnificos: no predica jamás. Cuando se conoce la fuerza de su fe y se sabe, de otra parte, el estrago que una religión acaso mal comprendida puede causar en el espiritu de ciertos escritores, nos sentimos tentados por aplicar también a Claudel la frase de Barbey d'Aurevilly sobre Baudelaire, y por admirar este prodigio de que rel artista no haya sido vencido.

Me falta el tiempo para hablaros del artista mismo y de su obra, no sólo en forma digna, sino convenientemente. Es inmenso el lugar que le concedo en nuestra literatura, y no trepido en declarar que Francia considerará algún día a Claudel como la Grecia antigua consideraba a Esquilo. la Italia al Dante e Inglaterra a Shakespeare. Estoy convencido, además, de que quedará en nuestra literatura como un accidente tan grandioso y tan aislado como los tres nombres que cité: los dos últimos lo son particularmente en sus respectivas literaturas. sin escuelas, propiamente dichas, sin continuadores; pero fuertes de belleza eterna y humana.

Pueden distinguirse dos partes en su obra: una parte trágica y una parte lírica, a las cuales es preciso agregar una magnifica recopilación de prosas sobre la China, Conocimientos del Estes, que sería tal vez para un profano la más natural introducción a su obra.

En su obra trágica, puédense hacer dos divisiones todavia: las tragedias del comienzo: Tête d'or. la Ville le Repos du Septième jour. IÉchange y la Jeune Fille Violaine; debe agregarse a éstas el Partage de Midi, acaso la obra maestra de Claudel, pero de la cual se hizo sólo una tirada de cien ejemplares, y que no será reimpresa en vida suya. Son. excepción hecha de l'Échange. tragedias dificilmente representables en que los diálogos familiares y líricos se mezclan y se entrecruzan. Los héroes hablan tanto el lenguaje de todos los dias. como el poeta les presta su inspiración. Pero cada uno de ellos continúa siendo un ser humano. a la vez simbólico y real; en medio de ellos muévense figuras de mujeres, de niñas. de una verdad, de una gracia y de una feminidad maravillosas.

La segunda serie de sus dramas comprende I'Annonce faife a Marie, drama de la Edad Media cristiana, segunda versión de la Jeune Fille Violaine. Protée. que es una especie de farsa satirica, y una trilogia, lOtage, le Pain dur y le Père Humilié, cuyos actos se desarrollan bajo la Revolución, el Imperio. la Francia de Luis Felipe y los dias de la Roma papal. En estos cuatro últimos dramas. Claudel ha concedido demasiado a las exigencias de la realización escénica y la mayor parte de ellos han sido representados en Alemania y en Paris antes de la guerra. en Praga, en Polonia y en Francia después de 1916.

En la obra lírica de Claudel, yo haría igualmente una división en dos partes: una comprende principalmente las cinco grandes Odas y el largo poema titulado Cefte heure qui est entre le printemps ét l'été. En estos poemas. Claudel hace uso de estrolas sin rimas, de extensión desigual. cuyo ritmo se adapta a las necesidades de la respiración humana o a los impulsos de la inspiración. Son para mí 
los más grandes trozos líricos de nuestra lengua, nuestras únicas odas comparables a los poemas bíblicos o pindáricos. Se desarrollan a través de incesantes creaciones de imágenes nuevas, en un esplendor poético de una riqueza inaudita y a su brillo verbal, va unido siempre, como en forma inmanente, un pensamiento seguro de si mismo; lo cual las diferencia, con ventaja para ellas, de los grandes poemas paganos o apocalípticos de Hugo, cuya belleza reside en la forma y cuya pobreza intelectual es verdaderamente lamentable. Habia querido leeros un fragmento de uno de estos primeros poemas líricos de Claudel; después he debido renunciar, en parte por no haber podido procurarme el volumen que deseaba, y. principalmente, porque un trozo tan reducido no podia haceros presentir su belleza. Preciso es que me creáis sobre mi palabra, o. lo que seria cien veces preferible, que vosotros mismos los busquéis y los leáis.

Sin renunciar enteramente a esta primera forma. Claudel debía, sin émbargo. modificarla después casi esencialmente. concediendo una parle a la rima. Se hizo asi el creador de un verso nuevo, más flexible y más lácilmente manejable que el alejandrino y que, si la inspiración se niega a satisfacer cada doce pies la rigurosa esclavitud de la rima, acepta, sin embargo, todo elemento de cadencia en el ritmo y frecuentemente toda la sorpresa de expresión que éste le aporta. El porvenir dirá la suerte que los escritores reservan a esta estrola claudeliana: entre los contemporáneos, no conozco sino dos que hayan tentado usarla, y es menester decir que este método poético aun está para nosotros demasiado impregnado del estilo mismo de Claudel y demasiado incorporado a la expresión propia de su pensamiento. para que semejantes ensayos no tengan obligadamente cierta apariencia de plagio. Voy a dar lectura a un poema de Claudel escrito enteramente en esta larga estrofa rimada o asonantada y que encuentro en su libro titulado Poèmes de guerre. En Francia, como en los demás países, por otra parte, la literatura de la guerra ha sido de una excepcional pobreza, y esta vulgaridad es mucho más señalada en la poesia que en la prosa. No conozco otros poemas de guerra verdaderamente hermosos que los de Guillaume Apollinaire y Paul Claudel, y éste que voy a leeros. ciertamente muy mal, recorrido de un extremo al otro por un soplo magnifico, os dará por lo menos una visión del lirismo de Claudel y de su técnica poética (1).

\section{II.-MARCEL PROUST}

$\mathrm{He}$ preferido estudiar los tres autores objeto de esta conferencia en el orden de su revelación al público. Explica esto que después de Claudel, dramaturgo. lírico y católico. llegue a Marcel Proust, novelista e incrédulo, cuyo aporte original a la novela francesa puede compararse con la amplitud obrada por Claudel en la tradición poética.

Marcel Proust nació en París el 10 de Julio de 1871. Su padre, el doctor

(1) Este poema ha sido inserfado en el volumen de Paul Claudel Poèmes de guerre bajo el titulo: Aux moris des Armées de la République. 
Proust, era un cirujano de gran renombre. Su madre pertenecía a una familia de origen israelita, convertida. Indico este último hecho. no porque convenga concederle extrema importancia, sino porque Marcel Proust será ciertamente objeto de uno de los más curiosos capitulos de ese libro aún por hacer sobre las influencias israelitas en la literatura francesa, y sobre las huellas dejadas por la herencia judia en la obra de algunos escritores franceses, desde Montaigne hasta Maurice Barrés.

Su existencia fué tan sedentaria como ha sido errante la de Claudel. Con la excepción de una larga permanencia en Venecia y de algunas travesias por el Mediterráneo. Marcel Proust no abandonó a Paris, sino por las playas normandas. Tenía la nostalgia de los viajes, pero dudo que tuviera por ellos un deseo verdadero; una cosa es soñar con Constantinopla o con Benares, y otra es saber adaptarse a todas las condiciones materiales de los largos cambios. Aunque realmente hubiese deseado viajar, su salud se lo habria impedido inmediatamente. Marcel Proust fué toda su vida un enfermo, un asmático, un nervioso, que llegó a temer por igual los sonidos, la luz, los perfumes demasiado fuertes. Después de haber desempeñado en una sociedad mundana muy reducida y en algunos pequeños grupos de la alta aristocracia francesa, un papel brillante, se retiró poco a poco de una existencia que lo agotaba, y donde, habria repartido toda su miel. Vivió los últimos años de su vida en una pieza tapizada de corcho. noche y dia alumbrada artificialmente, de donde no salia sino raras veces, de noche, para ir a despertar a algún amigo; entregado hasta la absorción completa de si mismo a la creación de esta obra imperecedera. Él mismo, en algunas frases admirables, ha indicado el secreto de esta soledad y revelado los lazos misteriosos que le tenian ligada al mundo de los vivos: Cuando era muy niño. ha escrito. la suerte de ninguno de los personajes de la historia santa me parecía tan miserable como la de Noé, a causa del diluvio que lo tuvo encerrado en el arca durante cuarenta dias. Más tarde estuve enfermo a menudo, y durante largos dias debí permanecer también en cel arcas. Entonces comprendi que Noé nunca pudo ver tan bien el mundo como desde el arca, así estuviera cerrada y fuera de noche sobre la tierra.

La muerte hirió a Marcel Proust en esta arca de silencio y de trabajo. el 18 de Noviembre. de 1922. Algunas semanas antes, había escrito la palabra sfin, en la última página de esta .Recherche $d u$ femps perdus, que es el monumento de su obra. Pero él la releía y hacía agregados sin cesar. Tenía otros proyectos en su imaginación, otras cosas que decir. y si nos colocamos en el punto de vista de la obra interrumpida, de la revelación que ya no será perfecta. debemos decir que su muerte causó a las letras francesas el duelo más irreparable que hayan sufrido desde la muerte de Baudelaire.

Se habia iniciado muy joven, a los 24 años. por una recopilación de Novelas y de Ensayos, ¿Les plaisirs ef les jours, algunas de cuyas páginas ya dejaban entrever al escritor de genio que más tarde seria, y de la cual no se vendieron, ciertamente. ni cincuenta ejemplares. Después fué el silencio completo durante cerca de veinte años, hasta 1913, en que publicó por cuenta suya, en 
casa del editor Bernard Grasset, el primer volumen de la -Recherche du temps perdu. . Du côté de chez Swann.. El mismo silencio casi universal, la misma apatía del público y de la crítica acogieron esta primera manifestación de uno de los más grandes escritores de que debía enorgullecerse nuestra literatura. Muy pocos fuimos aquéllos a quienes esta lectura entusiasmó y que hicimos lo que estuvo de nuestra mano para propagar este entusiasmo. Pero entonces no teníamos a nuestra disposición ninguno de los numerosos medios de propaganda de que, muy felizmente, puede hacer uso hoy la joven escuela. Un articulo que escribi para la Revista d'Italia, periódico romano que me habia encargado la critica de libros franceses. llegó a poder suyo la vispera de la declaración de guerra. Jamás apareció, naturalmente, y a menudo lo he lamentado, pues en la vida no tenemos muy a menudo la ocasión de hablar casi los primeros de alguna cosa nueva y auténtica.

En 1919. después de un primer rechazo del editor Grasset y de largas dudas. la Nouvelle Revue Française, que ha publicado. sea dicho de paso. a los mejores escritores de los últimos quince años, aceptó editar - A $\Gamma$ ombre des jeunes filles en fleurs, continuación de .Du côté de chez Swann.. En cinco años, el gusto literario en Francia habia experimentado una notable evolución: timidos en un comienzo. repetidos después y cada vez más decididos, los artículos elogiosos fueron apareciendo en la prensa, La Academia Goncourt, en fin, se honró para siempre discerniendo a Marcel Proust el homenaje de su premio anual y entregando su nombre y su obra a la atención del gran público francés y extranjero. Fué la gloria; no la diosa de alas postisas que saca a veces de la nada a un Rostand o a un Luis Hémon y les discierne sus coronas de cartón dorado; sino este renombre que lleva el culto de un artista al corazón de un grupo selecto cada día aumentado y que le ofrece el asentimiento de sus iguales.

Han aparecido, aparecen cada dia en el mundo entero innumerables novelas: tanto, que esta forma literaria cada dia más invasora. parece colocarse en nuestra época en el lugar que ocupaban antes el poema. la disertación o la tragedia. En qué se distinguen las novelas de Proust de esta inmensa producción contemporánea, con qué novedades nos han enriquecido: he aqui lo que yo querria exponeros muy sumariamente.

Podria decirse que hasta Proust la novela francesa se desenvolvia en superficie y que Proust le ha agregado una tercera dimensión. la profundidad. Muy bien sé lo que semejante declaración tiene de incompleto y de inexacto y todo lo que podría objetársele inmediatamente. Pero, en fin. no me parece menos efectivo que el novelista francés del siglo XIX. preocupado sobre todo por la claridad y la proporción, no llega a decirnos de sus personajes sino lo extrictamente necesario para hacerlos verosímiles y vivientes, y que estos personajes mismos no existen lo más a menudo en su obra sino en función de la obra misma, de su intriga, de su tesis o del caso psicológico que ella se propone estudiar. Estudia conflictos. caracteres, tipos morales. es decir. en un individuo. ella aisla lo que hay de más universal, en vez de ahondar en lo que hay de más irreductible. $Y$ es esto lo que explica que en esta novela encontremos frecuentemente a los demás, a quienes 
conocemos en su superficie, y nó a nosotros mismos, que nos conocemos por dentro.

Digo la novela francesa y nó la novela en general, porque existen por lo menos dos grandes escritores extranjeros que han introducido en su obra esta plenitud que Marcel Proust habia de hacer desbordar en sus libros: una inglesa. George Eliott y un ruso. Dostoiewsky. El autor de Moulin sur la Floss y de Middlemarch: el autor de Crimen y Casfigo y de El Idiota, tuvieron uno y otro sobre Marcel Proust una influencia considerable, y es sin duda a través de ellos como las posibilidades de enriquecimiento indefinido que una psicología menos abstracta, un análisis del hombre extendido a todo el hombre, podían aportar a la novela francesa, han aparecido en ella. El tercer gran maestro de Marcel Proust es Saint Simon. Sería interesantisimo señalar cómo era casi inevitable que fuera asi y por qué la novela francesa, si continúa la via abierta por Marcel Proust, se engarzará a la tradición de los memorialistas que hacen el retrato de sus contemporáneos y los dibujan según todas sus fases. como la novela clásica se engarza a la tradición de los trágicos, que no cogen al hombre sino en un momento de su vida y en un solo aspecto de su carácter. Pero estas disertaciones serán el cometido de los prolesores de la Sorbona que dentro de unos cincuenta años sucederán en esta cátedra de vuestra Universidad a M. Paul Hazard y hablarán a vuestros nietos de Marcel Proust menos brillantemente, sin duda, de lo que él nos habla de Chateaubriand. Por mi parte, yo debo hacer un camino más corto y más apresurado.

La gran novedad que ha traido Marcel Proust es, pues, la ampliación casi ilimitada del campo psicológico abierto al análisis del novelista. Bajo la incisión de esta visión clarísima, las pasiones más elementales, como el amor o los celos. son puestas al desnudo y disecadas, no como hasta él se hacia, en sus manifestaciones exteriores y conscientes, sino en los elementos mismos que las constituyen y cuyas reacciones, unas sobre otras. forman lo que habiamos tomado erradamente como algo elemental. Juntamente. los movimientos más fugaces del alma, las impresiones más pasajeras de los sentidos, son percibidas, anotadas. descritas, no en estado aislado, sino tal como se encadenan y entrecruzan en el continuo fluir de nuestra duración: y el novelista las ataca entre ellas y las relaciona con el individuo que es el teatro de su desarrollo. tanto por las vías misteriosas de lo inconsciente, tanto en la plena luz de la voluntad libre.

A los ojos de Marcel Proust, como a los de cualquier gran artista, todo lo que existe tiene su derecho respecto del observador: felizmente, no es un moralista que juzga y separa; su obra no es la de un partidario, sino más bien la de un clínico: tal es lo que le permite disecar ante vosotros con la misma desenvoltura y la misma lucidez, el snobismo de una duquesa y la abnegación terrible de una vieja sirvienta. las desviaciones más monstruosas del amor y los matices más impalpables y refinados del sentimiento.

A esta facultad casi extraordinaria de penetración y de análisis, a esta aguda inteligencia que le impulsa a penetrar esas regiones aun inexploradas del corazón humano, une Marcel Proust todas las cualidades del arte más necesarias 
al novelista. Tiene el dón de la vida: los personajes accesorios que señala con algunos trazos son tan reales ante nosotros como aquéllos de los cuales no hay un solo rincón del alma que él no haya escudriñado. Nos restituye, por un mimetismo extraordinario, la conversación exacta de las personas más diversas. Tiene la seguridad de la linea, la sobriedad y la juzteza de la imagen: tiene el gusto: sus novelas están sembradas de numerosas reflexiones criticas sobre tales o cuales obras de arte. cuya verdad e ingenio a menudo asombran. Por fin. tiene el estilo. La censura más seria que algunos hicieron a los primeros volúmenes de su obra, cuando ésta comenzaba a aparecer. fué el que estuvieran mal escritos: este reproche, me apresuro a decirlo, no salió de la pluma de ningún literato verdadero: pero la critica ha tenido siempre sus pobres de espíritu; cierto público formulaba también la misma censura.

El estilo de Proust no es, indudablemente. el estilo de todo el mundo, ni el mosaico artificial por el cual un Bourget imagina asemejarse a Balzac, ni la pulcra y Tácil prosa con que algunos de sus colegas de la Academia creen dar la impresión de facilidad y de pureza. De un extremo al otro de su obra. Marcel Proust ha usado una frase que le es propia, larga, muy larga. llena de incidentes, de sinuosidades, de vueltas sobre sí misma, y que parece serpentear a través de todas las curvas de la realidad. Estilo que se parece al de Saint Simon y que es un gran estilo. pues busca ante todo ser una expresión, seguir tan de cerca como sea posible la forma de la realidad y presentárnosla tangible y aprehensible. Es preciso no confundir estilo y composición; no os engañéis acerca de esto: Stendhal o de Balzac, por una parte, y Flaubert, por otra: son los dos primeros los que escriben mejor. porque en ellos el estilo forma un cuerpo inseparable de la obra, mientras que todas las decoraciones del lenguaje en Flaubert siguen siendo algo extraño, generalmente. a la obra misma. Desde este punto de vista. no hay novelas más mal escritas que las de Hugo. con todas las ampulosidades de la frase, y no hay ninguna mejor escrita que las de Lesage y de Stendhal, cuyo estilo, a la vez profundamente personal y anónimo, en ningún momento trata de desviar, en busca de ornamentos pintorescos o poéticos. una atención que su solo objeto exige toda entera. Debiendo expresar matices del sentimiento y describir estados de espiritu que nadie. en ninguna literatura. había analizado antes de él. Marcel Proust ha debido crear un estilo subordinado estrechamente a las necesidades de esta tarea. Lo que tenia que decir, no habria podido decirlo de otra manera. y él ha dicho todo lo que tenía que decir. Basta esto para que un estremecimiento de vida ininterrumpido circule desde el comienzo hasta el fin de estas largas frases, para que los personajes salgan de estas páginas con tanta vida como de las páginas de Balzac y para hacer de Proust tan grande escritor como gran psicólogo y gran novelista.

No puedo pensar en leeros un extracto de esta obra. No hay autor alguno del cual sea más dificil aislar una página que lo es de Marcel Proust. a causa de ese fluir indivisible que atraviesa. desde el comienzo hasta el fin. sus novelas. Ha relatado en ellas su vida, toda su vida, desde sus primeras impresiones de la infancia, traidas a la claridad y analizadas con una lucidez admirable y casi 
desesperante. Alrededor de este héroe principal, se agitan otros personajes estudiados en sí mismos, y no en sus relaciones con el autor, auscultados hasta el londo con una minuciosidad y una porfia que no dejan en sombras a ninguno de los ángeles o de los demonios que han hecho su reino del alma humana. Marcel Proust. hasta su hora última. se inmoló a estas exigencias sin reposo de su Arte. El mismo día de su muerte, invadido ya por los primeros estertores de la agonía, aun observaba, por un supremo esfuerzo de la voluntad, y borroneando sobre trozos de papel algunas notas. las entregaba a aquéllos que le rodeaban. diciéndoles: Esto podría servir para la muerte de Bergotte, uno de los personajes de sus primeros libros.

Es la muerte de un héroe, y tal como la escribió él de Bergotte: ‘Fué enterrado: pero toda la noche lúnebre, en las vitrinas alumbradas, sus libros, dispuestos de tres en tres, velaban como ángeles con las alas desplegadas y parecían, para aquél que ya no existía, el símbolo de la resurreccións.

\section{III._PAUL VALÉRY}

Con Paul Valéry, a quien es preciso no confundir con Valéry Larbaud, alcanzamos nuevamente una de las cimas más altas y más puras de la poesía francesa. Temo no llegar a daros, en los pocos instantes que me quedan, una idea digna de su obra; pero, a lo menos, querría que después de haber retenido su nombre. os quedara el deseo de conocerlo y de comprenderlo.

Paul Valéry nació en Cette en 1871. Muy joven, a los 22 años, publicó en algunas revistas simbolistas, principalmente en la Conque, que no alcanzó sino tres números, y en le Centaure, algunos raros poemas. En la „Nouvelle Revue, de Mme. Adam entregó, hacia la misma época, una sintroducción al método de Leonardo de Vincis y publicó sUna velada con $M$. Testes, que son, ambos, ensayos sobre la psicología del hombre de genio que ha llegado al conocimiento perfecto y al desasimiento absoluto de todas las cosas. Era en esta época el amigo y el discípulo predilecto de Stéphane Mallarmé, de quien fué ejecutor testamentario. Después dejó de escribir y calló en absoluto durante veinte años. dando todos sus ocios al estudio de la metalísica y de las matemáticas superiores. Las primeras lineas impresas que señalaron al público francés la existencia y la extraordinaria importancia de los trabajos de Einstein aparecieron en la "Nouvelle Revue Française», firmadas por Valéry. Era en 1919. En esta lecha, acababa de romper su silencio de veinte años. publicando en las mismas ediciones de la .Nouvelle Revue Française, un poema que hoy es imposible encontrar: -La jeune Parque. Vinieron en seguida un .Album de vers anciens, editado por Les amis des livres, y . Charmes, recopilación de poemas nuevos, por la Nouvelle Revue Française; después, un volumen que contiene dos diálogos en prosa, titulado Epaulinos ou $I$ archifecte. Todos estos volúmenes se encuentran ya agotados, pero se anuncia una próxima edición de sus poemas en que será reunida toda su obra en verso.

La censura que un espiritu superficial podría hacer desde luego a la poesía 
de Valéry seria el ser obscura y difícil. Esta censura, que se hizo valer por largo tiempo contra las obras de Mallarmé, puede significar dos cosas. Puede equivaler, indudablemente. a que un autor sea incomprensible: pero puede querer decir también que somos demasiado ignorantes, o demasiado perezosos o demasiados habituados a otro lenguaje, para comprenderlo. Una ecuación de segundo grado parece abscura al que no sabe resolver sino una regla de tres, y un lector de los folletines del Pelit Journal o de Matin. no comprenderá casi nada en una primera lectura de una tragedia de Racine. Así mismo. Valéry parecerá talvez obscuro si se comparan sus poemas con los de Francois Coppée o los de André Theuriet, pero esto sería en la misma relación en que los poemas de Vigny parecian incomprensibles a los lectores del abate Delile o del Caballero Parny. $\mathrm{Y}$ no hay un solo lector culto que, con un poco de atención, no descubra, mucho más fácilmente que en Mallarmé o los poetas Cubistas, sus incomparables bellezas.

Las novedades con que Veléry ha enriquecido nuestra literatura son, por lo demás, del orden de la poesía pura. y nó de la técnica. Valéry hace uso. en efecto. del verso clásico francés más tradicional y observa casi todas las reglas de la prosodia, tales como las fijó el siglo diecisiete. Respeta la cesura, la alternación de las rimas masculinas y femeninas y rima con tanta riqueza como su maestro Stephane Mallarmé: pero en este vaso antiguo vacia un licor precioso, desconocido antes de él, del cual quisiera haceros presentir siquiera las rarezas y el encanto.

Tres cualidades principales enriquecen a mi manera de ver los poemas de Valéry: la música, el pensamiento, el empleo renovado de las imágenes y de los epítetos.

En una carta que me escribía en la primavera de 1912, me decía lo siguiente: .El verso debe ser una vacilación extrañamente prolongada entre el sonido y el sentido, un viviente equilibrio que lamento haber roto en mis. Llamo un momento vuestra atención acerca de esta magnífica definición del verso: ¿Una vacilación extrañamente prolongada entre el sonido y el sentido.... Si el sentido. la significación literal, lo dominan, caeremos en los versos prosaicos y llanos de tantos despreciables autores; si la sonoridad musical es el todo. llegaremos a esos poemas de la vejez de Hugo. esas grandes tempestades verbales de la - Pifié suprème, de sl'Ane, de sDieu, tan espléndidos, por lo demás, como orquestación, pero tan lamentablemente vacíos y huecos. Que se establezca. por lo contrario, entre la música y el sentido ese viviente equilibrio de que habla Valéry, esa doble y perfecta solicitación de la inteligencia y de la sensibilidad. y nos hallaremos entonces ante uno de esos supremos términos que señalan desde Racine hasta André Chenier, desde Alfred de Vigny hasta Gérard de Nerval. desde Baudelaire hasta Mallarmé, las cimas de la poesía francesa.

Ahora bien, Valéry nos hace escuchar esta música sabia que puede surgir de las palabras. He aqui algunos versos, por ejemplo. que pone en boca de Narciso, cuando el pastor, inclinado sobre el agua, se dirige a su imagen, que la noche que cae va a borrar: 
.O semblable... Et pourtant plus parfait que moi-même.

Ephemère immortel si clair devant mes yeux.

Pales membres de perle, et ces cheveux soyeux.

Faut-il qu'à peine aimés l'ombre les obscurcisse.

Et que la nuit déjà nous divise. o Narcisse.

Et glisse entre nous deux le fer qui coupe un fruit.

O bien evocando a Semiramis. que contempla desde sus jardines la construcción de Babilonia, y poniendo en sus labios estas bellas estrofas:

.C'est une vaste peau fauve que mon royaume.

$J$ 'ai tué... le lion qui portait cette peau;

Mais encor le fumet du féroce fantôme

Flotte chargè de mort. et garde mon troupeau.

Repas de ma puissance, intelligible orgise.

Quel parvis vaporeux de toits et de forèts

place aux pieds de la pure et divine vigie.

Ce calme éloignement d'événements secrets.

Anxieuse d'azur, de gloire consumée.

Poitrine, gouffre d'ombre aux narines de chair.

Aspire cet encens d'âmes et de fumée

Qui monte diune ville analogue a la mer.

Soleil, soleil, regarde en toi rire mes ruches,

L'intense et sans répos Babylone bruit.

Toute rumeur de chars, clairons, chaines de cruches

Et plaintes de la pierre au mortel qui construit.

Qu'ils flattent mon désir de temples implacables.

Les sons aigus de scie et les cris des ciseaux.

Et ces gémissements de marbres et de cables

Qui peuplent l'air vivant de structure et d'oiseaux.

Pero esta música perfecta no es el único prestigio de Valéry: sólo sirve de acompañamiento al cortejo luminoso de las ideas. Paul Valéry, yo puedo testificarlo, es hoy en Francia una de las más bellas y más lucidas inteligencias, uno de los más extraordinarios espíritus metafísicos que se puedan encontrar. Es, como lo fueron Mallarmé. Baudelaire. Goethe, uno de esos elegidos en número infimo. en quienes la inteligencia y el espíritu poético han ido juntos hasta el fin. y que son a la vez, en el profundo y pleno sentido de estas palabras, poetas y filósofos. Creo que jamás se han escrito en Francia poemas más penetrados de inteligencia que Cimetière marin por ejemplo. o Serpent. que encontraréis en el volú- 
men Charmes. El amor. la voluptuosidad. las diversas pasiones que agitan el corazón de los hombres, parecen ausentes casi de la obra de Valéry: en todo caso, no se expresan jamás como en la obra de los románticos. en estado bruto: no las vemos sino transfiguradas de cierta manera en un alto dominio espiritual. Desde este punto de vista, podría decirse que su poesía es poesía platónica. que del mundo exterior y de nosotros mismos, nos entrega la transposición, el doble con nueva existencia en el mundo de las Ideas.

Tiene igualmente el sentido de la elipsis, el de recoger brusca y repentinamente. en pocas palabras, una escena o una visión inmensa. Quiere descubrir. por ejemplo, un árbol agitado hacia todos los lados por la tempestad y que parece una llama azotada por el viento. siempre renaciente y escribe estos cuatro versos magníficos, todos indispensables. todos necesarios, con esa necesidad que sólo el genio puede imprimir a sus obras:

.Flagelle toi... parais l'impatient martyr.

Qui soi-même s'écorche,

Et dispute a la flamme impuissante à partir

Ses retours vers la torche.

Lo que aquí hay de hermoso no es solamente la novedad de la imagen: es su extremada concisión en la Expresión. esta manera de presentar como de golpe una semejanza, una comparación, que otros poetas desarrollarían en numerosos versos. Es en esto en lo que Valéry está unido a la alta tradición clásica y a la magnifica sobriedad de Racine.

Unid a esto una riqueza y una vivacidad de imágenes casi sin par y el genio en la distribución y acercamiento de las palabras más usuales y casi las más usadas, que en su conjunto, hacen resplandecer un nuevo lenguaje.

Quiero daros lectura a uno de los más hermosos poemas de Charmes, titulado Palme, a lo largo del cual esas cualidades musicales, de pensamiento y de invención poética acumúlanse y se multiplican, sin turbar jamás la ordenación clásica ni la majestuosa serenidad del poema. Supone el poeta que en la tranquilidad de la vida doméstica, dirigiéndose a él, un Angel le revela como un ejemplo esta palma que en el desierto sostiene y madura lentamente sus frutos; durante dias y días, se realiza la obra secreta de la creación bajo la palma inclinada como en el alma del poeta; la palma y el poeta podrían desesperarse no viendo terminada la madurez, hasta el día en que los frutos. como la obra. se desprenden súbitamente de la palma o del espiritu.

Al terminar esta conferencia, experimento a la vez el pesar de haber sido tan breve y el temor de haberme extendido demasiado. A los tres autores que he estudiado, habría debido agregar, para haber sido completo. el nombre de André Gide, el novelista de Par la porte étroite y de Les Caves du Vafican. 
el gran lírico de Nourritures terrestres, y habria tenido asi una idea sumaria de los cuatro maestros a los cuales, de una manera o de otra, voluntariamente - a pesar suyo. está ligado todo lo que hay de algún valor en la -moderna escuela francesa. De esta escuela misma, de los escritores tan diversos y tan interesantes que comprende, de Valéry Larbaud a Paul Morand, de León-Paul Fargue a Giraudoux, de Jean Cocteau a Henri de Montherlant, de Guillaume Apollinaire a Sanit John Perse, habria cosas apasionadas que deciros.

Por este contacto con el arte francés viviente, estoy seguro de que muchos prejuicios que se han formado aquí como en otras partes, acerca de esta gente joven, se desharian; y que vosotros descubririais una lase de nuestra literatura que atrae y seduce en forma diversa de lo que pueden ofreceros algunos viejos contemporáneos demasiado conocidos y que no deseo nombrar una vez más.

Que me sea permitido esperar, por lo menos, que en algo os haya inspirado el deseo de conocerlos y que esta puerta apenas entreabierta por mí, será abierta y franqueada por vosotros. Quiero agregar que durante todo el tiempo que tenga el placer de estar entre vosotros, quedaré a disposición de toda persona que desee algún dato o esclarecer algún punto en lo que toca al actual movimiento artístico de Francia. Daré respuesta a una carta en que se me pregunte qué libro debe leerse de Francis Jammes, o quién es Valéry Larbaud, o cuál es la importancia de Jules Romains, con tanta exactitud y no sin mayor placer. que a aquéllas otras en que se me interroga sobre las tarifas aduaneras de las lentejas o de los nitratos. Siempre he pensado que una Legación de Francia no debe ser sólo una oficina donde se refrendan pasaportes diplomáticos y donde se cambian palabras cumplidas entre gentes amables, sino una casa de donde todo lo que es la Francia viviente, la Francia de las Artes como la Francia de las Ideas. debe irradiar y difundirse. Así es como podremos trabajar con mayor utilidad para estrechar entre vuestra patria y la mía. entre estas dos naciones impregnadas de las grandes tradiciones latinas y democráticas. esta viva y ya vieja amistad. que no solamente ha de traernos flores retóricas para los discursos oficiales, sino afirmarse en la comprensión reciproca, en el comercio lecundo y desinteresado de su selección intelectual.

HENRI HOPPENOT.

(M. Henri Hoppenot tuvo la gentileza de enviar a nuestra Revista el inferesantisimo estudio que anfecede. Pocas cosas más gratas para nosotros que publicar en las páginas anferiores, la fraducción de esfa conferencia). 